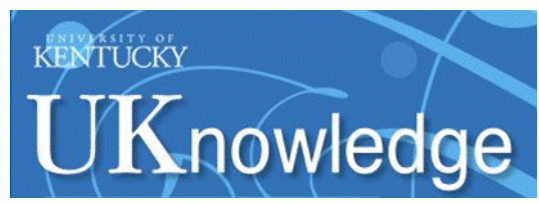

University of Kentucky

UKnowledge

$1-1-2017$

\title{
Telotristat Ethyl, a Tryptophan Hydroxylase Inhibitor for the Treatment of Carcinoid Syndrome
}

\author{
Matthew H. Kulke \\ Dana-Farber Cancer Institute \\ Dieter Hörsch \\ Zentralklinik Bad Berka, Germany \\ Martyn E. Caplin \\ Royal Free Hospital, UK \\ Lowell B. Anthony \\ University of Kentucky, lowell.anthony@uky.edu \\ Emily Bergsland \\ University of California - San Francisco

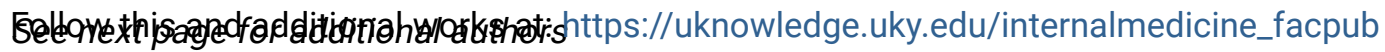 \\ Part of the Oncology Commons \\ Right click to open a feedback form in a new tab to let us know how this document benefits you.

\section{Repository Citation} \\ Kulke, Matthew H.; Hörsch, Dieter; Caplin, Martyn E.; Anthony, Lowell B.; Bergsland, Emily; Öberg, Kjell; \\ Welin, Staffan; Warner, Richard R. P.; Lombard-Bohas, Catherine; Kunz, Pamela L.; Grande, Enrique; Valle, \\ Juan W.; Fleming, Douglas; Lapuerta, Pablo; Banks, Phillip; Jackson, Shanna; Zambrowicz, Brian; Sands, \\ Arthur T.; and Pavel, Marianne, "Telotristat Ethyl, a Tryptophan Hydroxylase Inhibitor for the Treatment of \\ Carcinoid Syndrome" (2017). Internal Medicine Faculty Publications. 134. \\ https://uknowledge.uky.edu/internalmedicine_facpub/134
}

This Article is brought to you for free and open access by the Internal Medicine at UKnowledge. It has been accepted for inclusion in Internal Medicine Faculty Publications by an authorized administrator of UKnowledge. For more information, please contact UKnowledge@lsv.uky.edu. 


\section{Telotristat Ethyl, a Tryptophan Hydroxylase Inhibitor for the Treatment of Carcinoid Syndrome}

Digital Object Identifier (DOI)

https://doi.org/10.1200/JCO.2016.69.2780

Notes/Citation Information

Published in Journal of Clinical Oncology, v. 35, no. 1, p. 14-23.

(C) 2016 by American Society of Clinical Oncology

The copyright holder has granted the permission for posting the article here.

\section{Authors}

Matthew H. Kulke, Dieter Hörsch, Martyn E. Caplin, Lowell B. Anthony, Emily Bergsland, Kjell Öberg, Staffan Welin, Richard R. P. Warner, Catherine Lombard-Bohas, Pamela L. Kunz, Enrique Grande, Juan W. Valle, Douglas Fleming, Pablo Lapuerta, Phillip Banks, Shanna Jackson, Brian Zambrowicz, Arthur T. Sands, and Marianne Pavel 
Author affiliations appear at the end of this article.

Published at ascopubs.org/journal/jco on October 31, 2016

Processed as a Rapid Communication manuscript.

Support information appears at the end of this article.

M.H.K. and D.H. contributed equally to this work.

Clinical trial information: NCT01677910

Corresponding author: Matthew H. Kulke, MD, Dana-Farber Cancer InstituteHarvard Medical School, 450 Brookline Ave, Boston, MA 02115; e-mail: Matthew_Kulke@dfci.harvard.edu.

(C) 2016 by American Society of Clinical Oncology

0732-183X/17/3501w-14w/\$20.00

\section{Telotristat Ethyl, a Tryptophan Hydroxylase Inhibitor for the Treatment of Carcinoid Syndrome}

Matthew H. Kulke, Dieter Hörsch, Martyn E. Caplin, Lowell B. Anthony, Emily Bergsland, Kjell Öberg, Staffan Welin, Richard R.P. Warner, Catherine Lombard-Bohas, Pamela L. Kunz, Enrique Grande, Juan W. Valle, Douglas Fleming, Pablo Lapuerta, Phillip Banks, Shanna Jackson, Brian Zambrowicz, Arthur T. Sands, and Marianne Pavel

\section{A $\begin{array}{llllllll}\text { B } & \text { S } & \text { T } & \text { R } & \text { A } & \text { C } & \text { T }\end{array}$}

\section{Purpose}

Preliminary studies suggested that telotristat ethyl, a tryptophan hydroxylase inhibitor, reduces bowel movement (BM) frequency in patients with carcinoid syndrome. This placebo-controlled phase III study evaluated telotristat ethyl in this setting.

\section{Patients and Methods}

Patients ( $N=135$ ) experiencing four or more BMs per day despite stable-dose somatostatin analog therapy received (1:1:1) placebo, telotristat ethyl $250 \mathrm{mg}$, or telotristat ethyl $500 \mathrm{mg}$ three times per day orally during a 12-week double-blind treatment period. The primary end point was change from baseline in BM frequency. In an open-label extension, 115 patients subsequently received telotristat ethyl $500 \mathrm{mg}$.

\section{Results}

Estimated differences in BM frequency per day versus placebo averaged over 12 weeks were -0.81 for telotristat ethyl $250 \mathrm{mg}(P<.001)$ and -0.69 for telotristat ethyl $500 \mathrm{mg}(P<.001)$. At week 12 , mean BM frequency reductions per day for placebo, telotristat ethyl $250 \mathrm{mg}$, and telotristat ethyl 500 mg were $-0.9,-1.7$, and -2.1 , respectively. Responses, predefined as a BM frequency reduction $\geq 30 \%$ from baseline for $\geq 50 \%$ of the double-blind treatment period, were observed in $20 \%, 44 \%$, and $42 \%$ of patients given placebo, telotristat ethyl $250 \mathrm{mg}$, and telotristat ethyl $500 \mathrm{mg}$, respectively. Both telotristat ethyl dosages significantly reduced mean urinary 5-hydroxyindole acetic acid versus placebo at week $12(P<.001)$. Mild nausea and asymptomatic increases in gamma-glutamyl transferase were observed in some patients receiving telotristat ethyl. Follow-up of patients during the open-label extension revealed no new safety signals and suggested sustained BM responses to treatment.

\section{Conclusion}

Among patients with carcinoid syndrome not adequately controlled by somatostatin analogs, treatment with telotristat ethyl was generally safe and well tolerated and resulted in significant reductions in BM frequency and urinary 5-hydroxyindole acetic acid.

\section{J Clin Oncol 35:14-23. (C) 2016 by American Society of Clinical Oncology}

\section{INTRODUCTION}

Patients with advanced neuroendocrine tumors (NETs) may develop carcinoid syndrome, a condition associated with tumoral secretion of serotonin and characterized by diarrhea, flushing, bronchial constriction, and the development of cardiac valvular fibrosis, which may lead to heart failure. ${ }^{1,2}$ Diarrhea, one of the most prominent symptoms of carcinoid syndrome, negatively affects patients' emotional well-being and social and physical functioning. ${ }^{3}$ Serotonin is metabolized into 5-hydyroxyindoleacetic acid (5-HIAA), a biomarker measurable in the urine and often used to follow treatment response in patients with carcinoid syndrome. ${ }^{4,5}$ High systemic serotonin levels, as reflected by elevated urinary 5-HIAA (u5-HIAA), most often in the setting of widespread tumor metastases, are associated with severe carcinoid syndrome, carcinoid heart disease, and poor prognosis. ${ }^{2,6,7}$

Somatostatin analogs (SSAs), the standard treatment for patients with carcinoid syndrome, are an effective initial treatment, but patients may develop recurrent symptoms during the course of 
their disease. ${ }^{4,8}$ Tryptophan hydroxylase (TPH), the rate-limiting enzyme in serotonin synthesis, converts tryptophan to 5hydroxytryptophan, which is subsequently converted to serotonin. ${ }^{5}$ The hypothesis that inhibiting TPH may reduce symptoms of carcinoid syndrome was tested in 1967 by Engelman et al ${ }^{9}$ with parachlorophenylalanine. In that study, symptoms improved and u5HIAA levels were reduced. However, parachlorophenylalanine crossed the blood-brain barrier, causing severe CNS-related adverse effects, including depression.

Telotristat ethyl is a novel, oral, small-molecule TPH inhibitor that has a high molecular weight and acidic moieties, which inhibit it from crossing the blood-brain barrier. ${ }^{5,10}$ Two early studies in patients with carcinoid syndrome suggested that telotristat etiprate, the hippurate salt of telotristat ethyl, reduced bowel movement (BM) frequency and decreased u5-HIAA without overt CNS adverse effects. ${ }^{1,12}$ Although the name "telotristat etiprate" was previously granted by the United States Adopted Names Council and has been used in the literature, ${ }^{11,12}$ recent guidance from the US Food and Drug Administration recommends using the name of the neutral form rather than the name of the salt for drug products. Therefore, telotristat ethyl is used herein. In this international, multicenter, randomized, double-blind, placebo-controlled phase III trial (TELESTAR), we assessed the safety and efficacy of telotristat ethyl in patients with carcinoid syndrome not adequately controlled with SSA therapy.

\section{PATIENTS AND METHODS}

\section{Patients}

Eligible patients were $\geq 18$ years of age, had histopathologically confirmed, well-differentiated metastatic NETs, had a documented history of carcinoid syndrome, were experiencing an average of four or more BMs per day, and were receiving stable-dose SSAs (long-acting release [LAR], depot, or infusion pump) for $\geq 3$ months before enrollment. Patients with u5-HIAA levels above or below the upper limit of normal (normal: 0 to $15 \mathrm{mg} / 24$ hours ${ }^{13}$ ) and those with unknown values at baseline were allowed to participate. Because of the risk of acute complications from severe diarrhea, patients experiencing more than 12 watery BMs per day associated with volume contraction, dehydration, or hypotension, or showing evidence of enteric infection were excluded. In addition, patients with a Karnofsky performance status $\leq 60 \%$, a history of short bowel syndrome, or clinically important baseline elevation in liver function tests were excluded. Patients were also excluded if they had recently undergone tumor-directed therapy. Additional exclusion criteria are described in the Data Supplement.

\section{Study Design and Treatment}

Patients entered a screening period of 3 or 4 weeks, depending upon their SSA dose schedule (typically administered every 3 to 4 weeks), ${ }^{14}$ to establish baseline symptoms. Patients were randomly assigned 1:1:1 to receive oral doses, three times per day for 12 weeks, of telotristat ethyl $250 \mathrm{mg}$, telotristat ethyl $500 \mathrm{mg}$, or placebo. Patients continued to receive their baseline SSA therapy for all 12 weeks. Rescue use of short-acting octreotide and antidiarrheal agents was allowed and unrestricted. After this doubleblind treatment (DBT) period, all patients were offered treatment with telotristat ethyl $500 \mathrm{mg}$ three times per day in a 36-week open-label extension (OLE). Downward dose adjustment was allowed in cases of intolerability. The OLE is currently ongoing. Conduct of the study was approved by the institutional review board or ethics committee at each center, and the study complied with Good Clinical Practice guidelines and the Declaration of Helsinki. All patients provided written informed consent.

\section{Efficacy and Safety Assessments}

All primary and secondary efficacy assessments, except u5-HIAA, were self-reported in daily electronic diaries. The primary end point of the study was mean reduction from baseline in daily BMs averaged over 12 weeks. Key secondary end points included change from baseline in u5HIAA at week 12, the number of daily flushing episodes, and abdominal pain severity (on a scale of 0 to 10 ) averaged over 12 weeks. Responders were prespecified as patients experiencing a $\geq 30 \%$ reduction in $\mathrm{BM}$ frequency (relative to baseline) for $\geq 50 \%$ of the DBT period. Additional efficacy end points included change from baseline in the European Organisation for Research and Treatment of Cancer Quality of Life Questionnaire-Core 30 (EORTC QLQ-C30) scores, rescue short-acting SSA use, stool consistency, and the proportion of days with urgency to defecate (Data Supplement). Patient use of over-the-counter antidiarrheals was not tracked in this study.

Adverse events (AEs) were graded as mild, moderate, or severe (Data Supplement). Depression-related AEs were events of special interest, and a validated two-question case-finding instrument was administered to all patients at each study visit. ${ }^{15}$ A pharmacokinetic analysis substudy was performed in 40 patients (Data Supplement). The planned efficacy analyses were based on the intent-to-treat population. However, a single patient initially randomly assigned to receive telotristat ethyl $500 \mathrm{mg}$ was subsequently deemed a screen failure and was not treated. This same patient was subsequently re-evaluated, found to meet all eligibility criteria, randomly assigned a second time to telotristat ethyl $250 \mathrm{mg}$, and included in the telotristat ethyl $250 \mathrm{mg}$ group for analysis of efficacy and safety. The safety population consisted of all patients who received at least one dose of the study drug.

\section{Statistical Analysis}

A blocked Wilcoxon rank sum statistic (stratified by baseline u5-HIAA levels) was used to evaluate the primary efficacy end point. The nonparametric Hodges-Lehmann estimator was used to describe the magnitude of the treatment effect. Parallel analyses were used for additional efficacy end points, including change from baseline in u5-HIAA level, number of flushing episodes, abdominal pain severity, EORTC QLQ-C30 scores, stool consistency, and the proportion of days with urgency to defecate. A Bonferronibased multiple comparison procedure with restrictions on the order of testing treatment group hypotheses was applied to control the local and overall type I error probabilities $(\alpha=.05)$ for the primary and secondary efficacy end points. A more detailed description of the statistical methods used in this study is provided in the Data Supplement.

\section{RESULTS}

\section{Patient Characteristics}

From January 31, 2013, to March 4, 2015, 135 patients from 12 countries were randomly assigned to receive telotristat ethyl $250 \mathrm{mg}$ or $500 \mathrm{mg}$ three times per day or placebo three times per day (Fig 1). Demographic and baseline characteristics were similar among groups (Table 1); 43\% of patients were receiving abovelabel doses of SSAs, defined as a cumulative dose of $>30 \mathrm{mg}$ octreotide LAR or $>120 \mathrm{mg}$ lanreotide over the course of 4 weeks. ${ }^{8,16}$ At baseline, mean daily BM frequency ranged from 5.2 to 6.1 counts per day and mean u5-HIAA levels ranged from 81.0 to $92.6 \mathrm{mg} / 24$ hours across all treatment groups. More than $57 \%$ of patients had u5-HIAA levels above the upper limit of normal.

\section{Patient Disposition}

In this study $(\mathrm{N}=135), 45$ patients received treatment in each study arm. A total of 136 random assignments occurred; one 


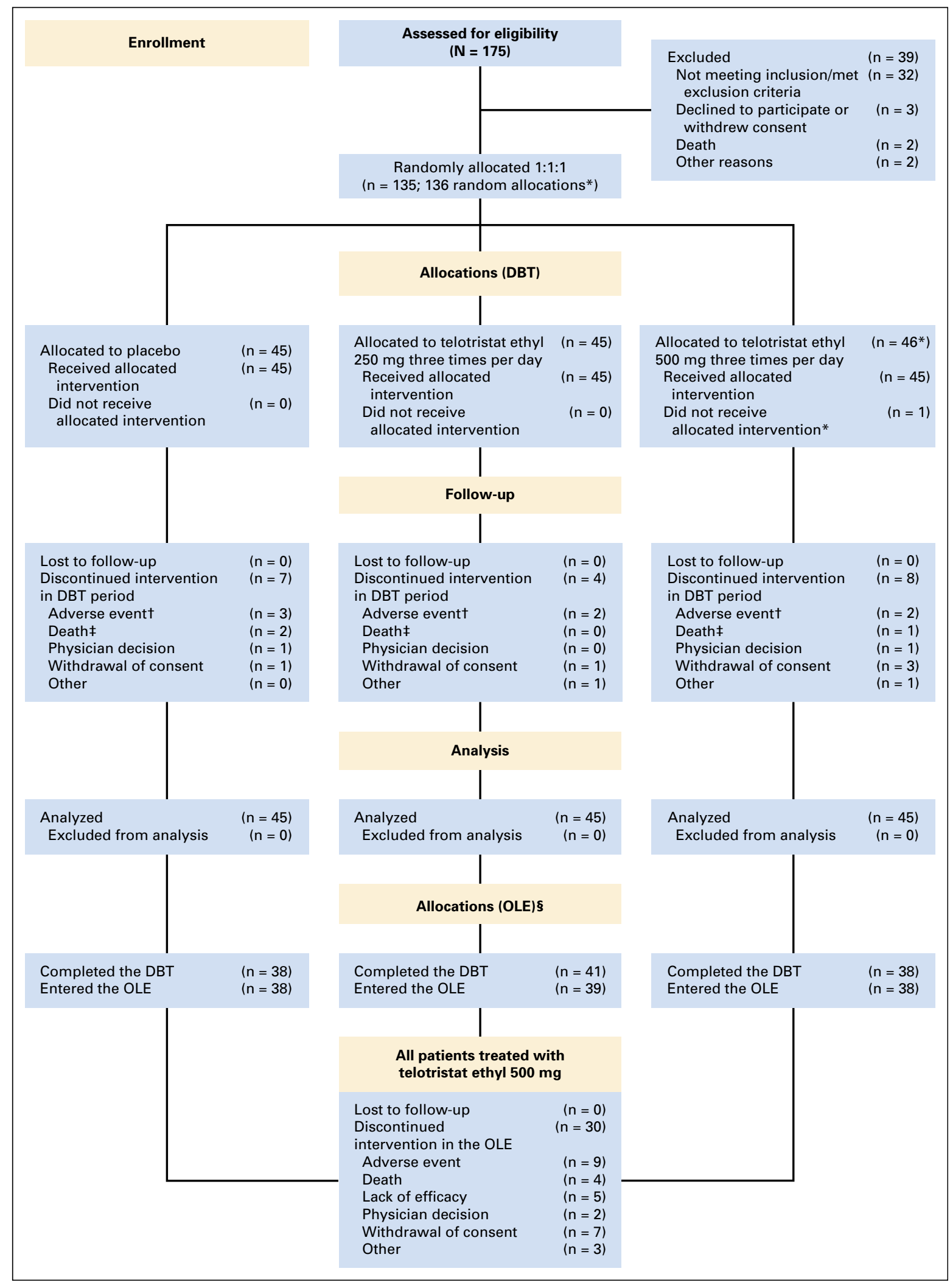

Fig 1. CONSORT diagram. Patient flow in the double-blind treatment (DBT) period of the TELESTAR study. $\left({ }^{*}\right)$ One patient initially randomly assigned to receive telotristat ethyl $500 \mathrm{mg}$ was designated a screen failure because of bruising found during physical examination. This patient was subsequently rescreened, met all eligibility criteria, and was subsequently randomly assigned a second time to telotristat ethyl $250 \mathrm{mg}$. This patient was included in the telotristat ethyl $250 \mathrm{mg}$ group for both efficacy and safety analyses. ( $\dagger$ ) Additional adverse events leading to study discontinuation are fully described in Table 3. (¥) A total of five deaths occurred after random assignment, but two patients (one each receiving placebo and telotristat ethyl $250 \mathrm{mg}$ three times per day) previously withdrew from the study because of adverse events. (§) Patient flow into the open-label extension (OLE) reflects data extracted from the interim clinical study report. 
Table 1. Demographic and Baseline Characteristics of the Patient Population

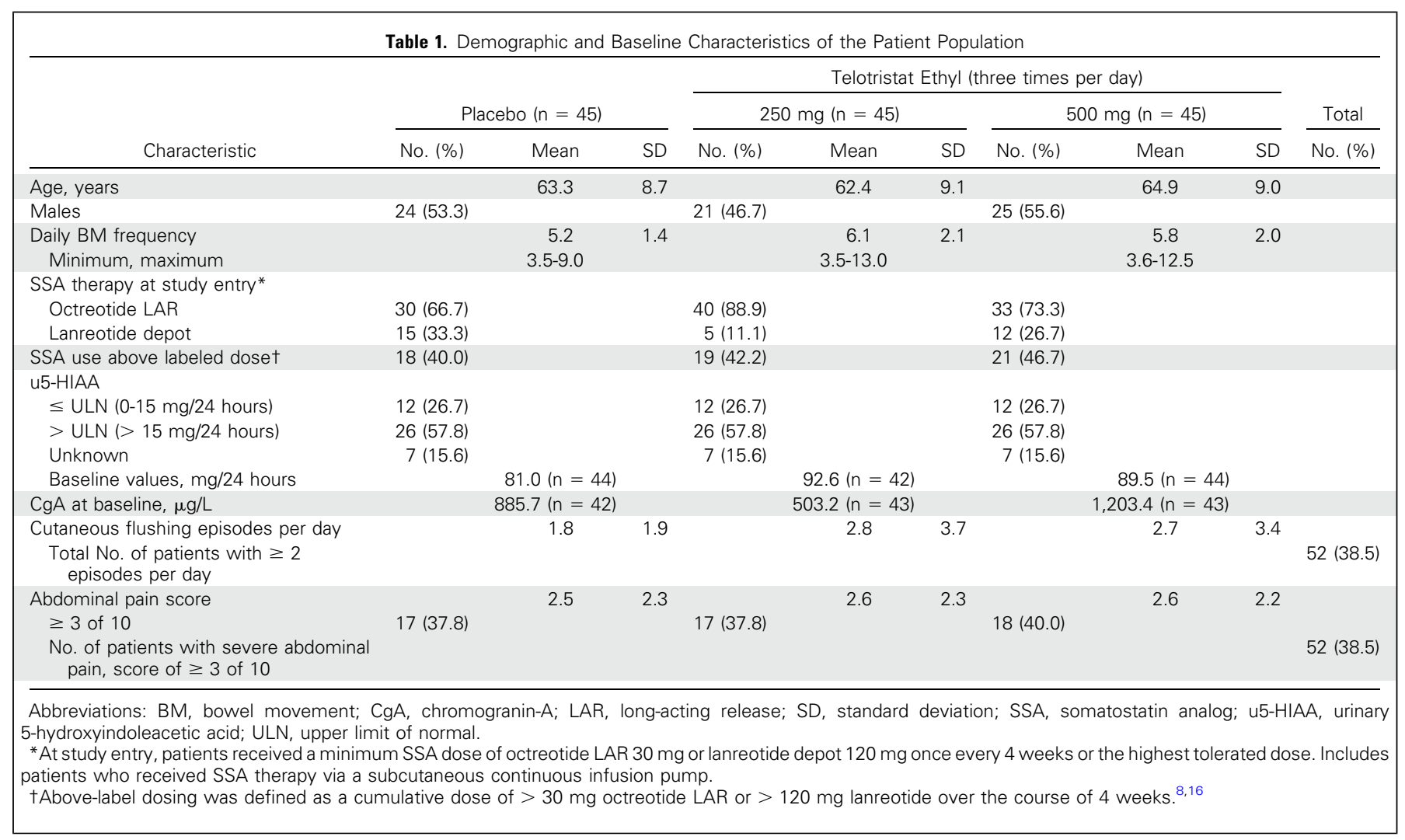

patient initially randomly assigned to the telotristat ethyl $500 \mathrm{mg}$ group and deemed a screen failure was rescreened and subsequently randomly assigned a second time to receive telotristat ethyl $250 \mathrm{mg}$ (Data Supplement). Forty-one patients (91.1\%) and 38 patients $(82.6 \%)$ in the telotristat ethyl $250 \mathrm{mg}$ and $500 \mathrm{mg}$ groups, respectively, and 38 patients $(84.4 \%)$ in the placebo group completed the DBT period. Compliance, defined as receipt of $75 \%$ to $125 \%$ of planned doses, was $93.3 \%$ and $86.7 \%$ in the telotristat ethyl $250 \mathrm{mg}$ and $500 \mathrm{mg}$ groups, respectively, and $86.7 \%$ in the placebo group. Use of short-acting rescue octreotide was slightly higher in the placebo group than in patients receiving telotristat ethyl (Appendix Fig A1, online only). At the time this article was prepared, 115 patients entered the OLE, 56 completed it, and 29 were currently receiving treatment. Mean treatment exposure was 26.7 weeks (range, 1.7 to 38.3 weeks).

\section{Efficacy}

$B M$ frequency. Treatment with telotristat ethyl at either dosage was associated with statistically significant reductions in BM frequency over time compared with placebo (Fig 2A). The HodgesLehmann estimator for patients receiving telotristat ethyl $250 \mathrm{mg}$ was -0.81 and -0.69 for those receiving telotristat ethyl $500 \mathrm{mg}$ $(P<.001)$. The arithmetic mean reduction in daily BM frequency from baseline to week 12 was -1.7 -and -2.1 with the telotristat ethyl $250 \mathrm{mg}$ and $500 \mathrm{mg}$, respectively, and -0.9 for the placebo (Fig 2B). Individual patient responses during the DBT period are shown in Figures 2C and 2D. In total, $44 \%$ and $42 \%$ of participants who received telotristat ethyl $250 \mathrm{mg}$ and $500 \mathrm{mg}$, respectively, were classified as BM responders versus $20 \%$ of patients who received the placebo. The odds ratios (ORs) were 3.49 (95\% CI, 1.33 to 9.16) and 3.11 (95\% CI, 1.20 to 8.10 ) for telotristat ethyl $250 \mathrm{mg}$ and $500 \mathrm{mg}$, respectively (Table 2). In the OLE, BM reductions were consistent with results from the DBT period (Fig 2A).

u5-HIAA. In patients who were evaluable at baseline and week 12, treatment with telotristat ethyl at either dosage was associated with statistically significant reductions in u5-HIAA levels compared with placebo. The Hodges-Lehmann estimator was $-30.1 \mathrm{mg} / 24$ hours and $-33.8 \mathrm{mg} / 24$ hours for telotristat ethyl $250 \mathrm{mg}$ and $500 \mathrm{mg}$, respectively $(P<.001$ for both). At week 12, arithmetic mean u5-HIAA levels decreased by $40.1 \mathrm{mg} / 24$ hours and by $57.7 \mathrm{mg} / 24$ hours in the telotristat ethyl $250 \mathrm{mg}$ and $500 \mathrm{mg}$ groups, respectively. The mean u5-HIAA levels increased in the placebo group by $11.5 \mathrm{mg} / 24$ hours at week 12 . Individual patient responses during the DBT period are shown in Figures $3 \mathrm{~A}$ and $3 \mathrm{~B}$. In a post hoc analysis of patients treated with telotristat ethyl, $78 \%$ $(\mathrm{n}=25)$ and $87 \%(\mathrm{n}=26)$ of patients in the $250 \mathrm{mg}$ and $500 \mathrm{mg}$ groups, respectively, experienced a $\geq 30 \%$ decrease in u5-HIAA levels compared with $10 \%(\mathrm{n}=3)$ in the placebo group.

Flushing and abdominal pain. Relatively few patients reported having two or more flushing episodes per day or abdominal pain (rating of $\geq 3$ of 10 in severity) at baseline (Table 1), and changes in these end points did not reach statistical significance (Appendix Table A1).

Quality of life and other end points. EORTC QLQ-C30 diarrhea subscale scores, which were averaged over the DBT period, improved by 19.2 points (on a scale of 0 to 100 ) and by 21.6 points in the telotristat ethyl $250 \mathrm{mg}$ and $500 \mathrm{mg}$ groups, respectively, and by only 8.5 points in the placebo group $(P=.039$ and $P=.051$ for 


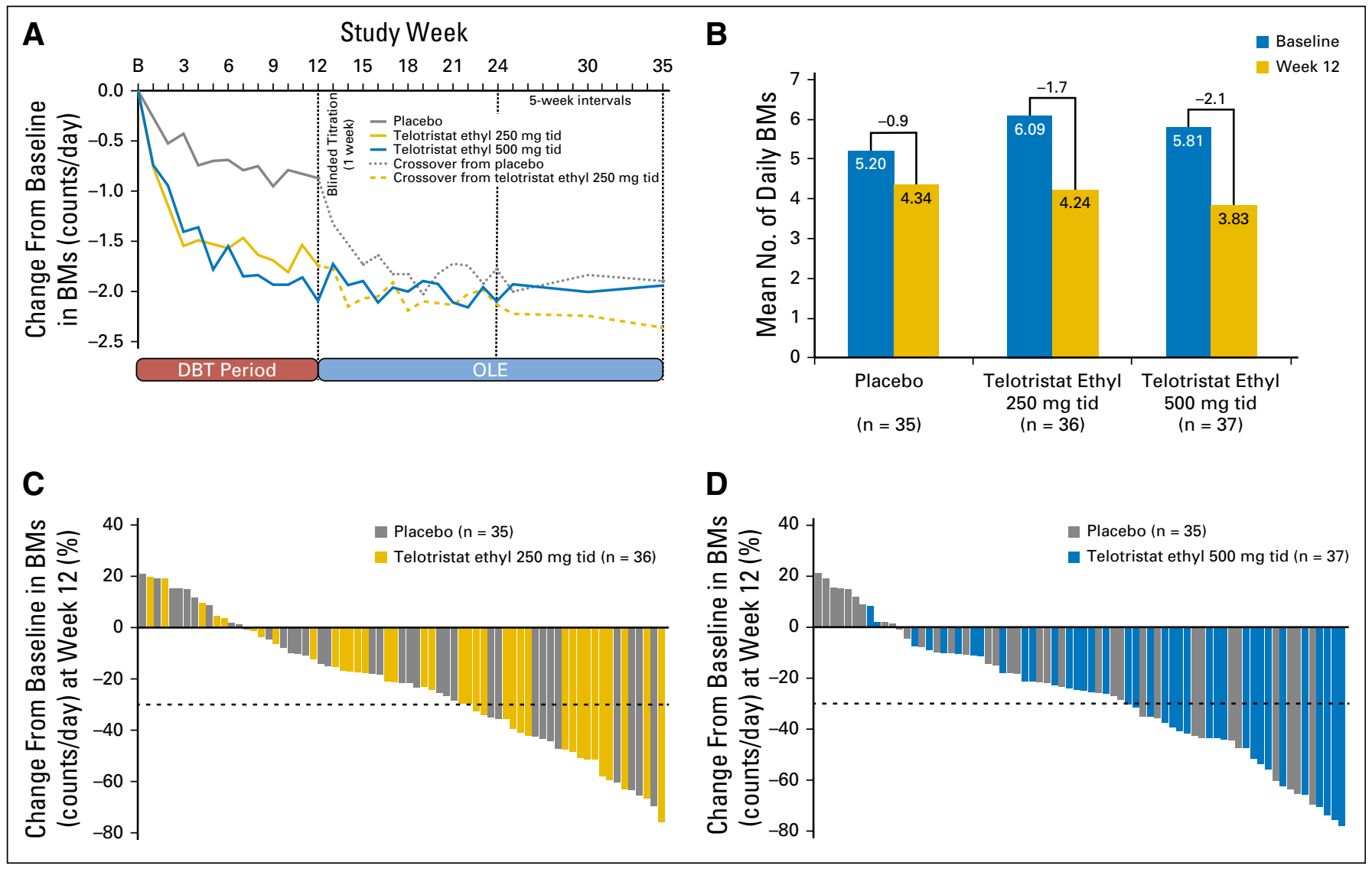

Fig 2. Change from baseline in frequency of bowel movements (BMs) in patients receiving placebo or telotristat ethyl ( $250 \mathrm{mg}$ or $500 \mathrm{mg}$ ) three times per day (tid). (A) Reduction

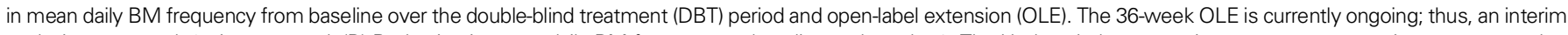

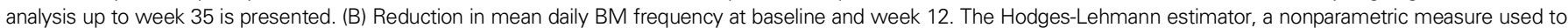

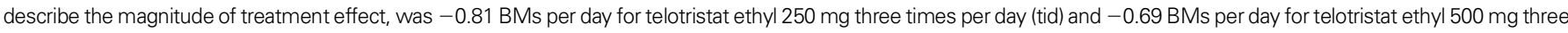

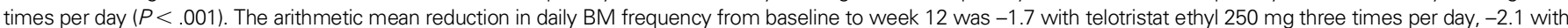

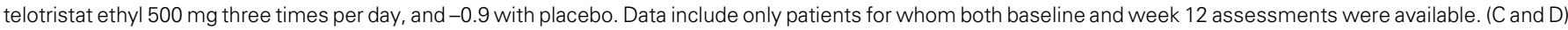

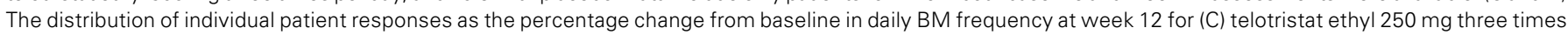

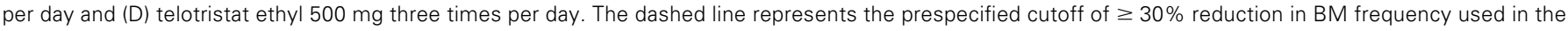
responder analysis.

telotristat ethyl $250 \mathrm{mg}$ and $500 \mathrm{mg}$, respectively.). No significant treatment group differences were observed in the nausea and vomiting subscale. No overall differences in the global health status subscale were observed between treatment arms, although patients classified as BM responders reported modest improvements in overall quality of life compared with nonresponders in all three treatment arms (Appendix Table A2). Some evidence that telotristat ethyl may also improve stool consistency, reduce the urgency to defecate, and reduce rescue short-acting octreotide use was observed (Appendix Table A1; Appendix Fig A1). Pharmacokinetic models also support a dose response to treatment of both u5-HIAA and BM frequency (Data Supplement).

\section{Safety}

The overall incidence of treatment-emergent adverse events (TEAEs) across the three treatment arms was similar (Table 3; Appendix Table A3). A higher incidence of nausea was noted in patients in the telotristat ethyl $500 \mathrm{mg}$ group (31.1\%) compared with patients in the telotristat ethyl $250 \mathrm{mg}$ group or the placebo group $(13.3 \%$ and $11.1 \%$, respectively). One patient receiving placebo discontinued the study drug because of nausea; however, no patients receiving telotristat ethyl discontinued because of nausea. Dose-related increases in hepatic enzymes, particularly gamma-glutamyl transferase, were observed in both telotristat ethyl groups (Table 3). In the DBT period, depressionrelated AEs, including depression, depressed mood, and decreased interest, occurred during treatment in $6.7 \%, 6.7 \%$, and $15.6 \%$ of patients in the placebo, telotristat ethyl $250 \mathrm{mg}$, and $500 \mathrm{mg}$ groups, respectively. However, no patient reporting depression required initiation of new antidepressant therapy, and no cases of depression resulted in treatment discontinuation. In the OLE, among patients who crossed over from placebo to telotristat ethyl $500 \mathrm{mg}$, there was only one new report of decreased interest, but no new reports of depression or depressed mood were made between weeks 12 and 24 (Appendix Table A4).

\section{DISCUSSION}

In this randomized, double-blind, placebo-controlled phase III study in patients with carcinoid syndrome not adequately 


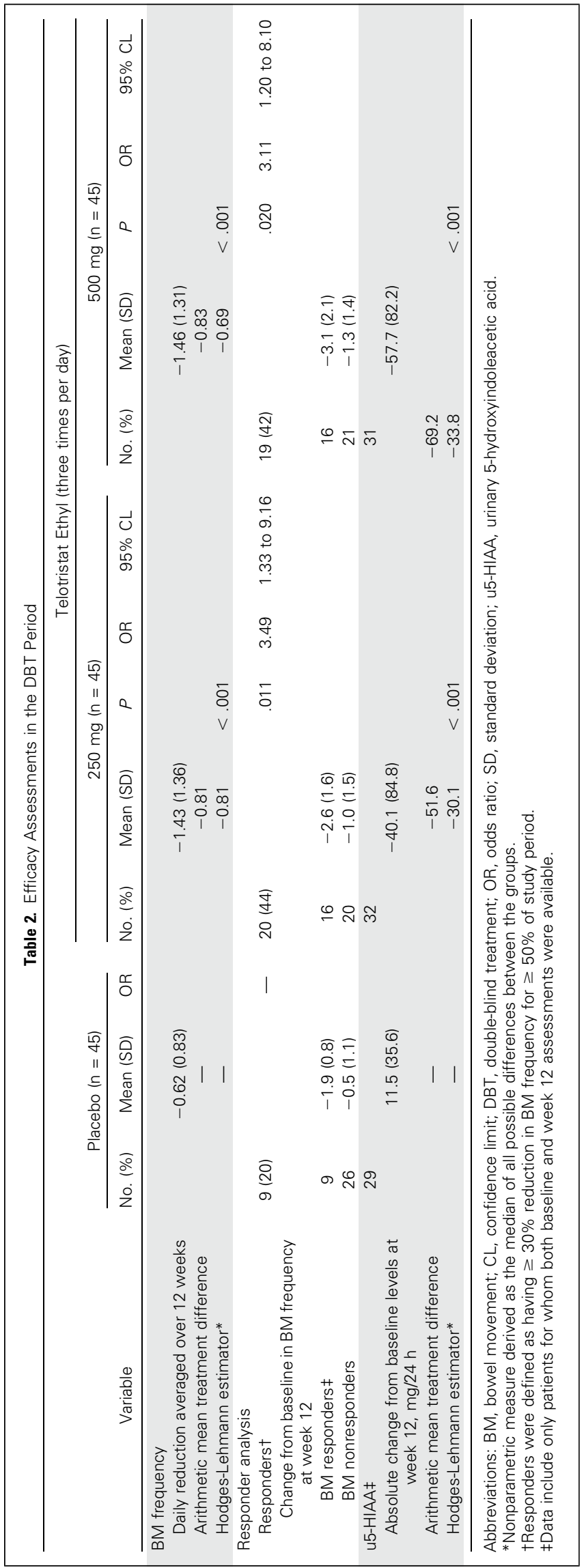


A

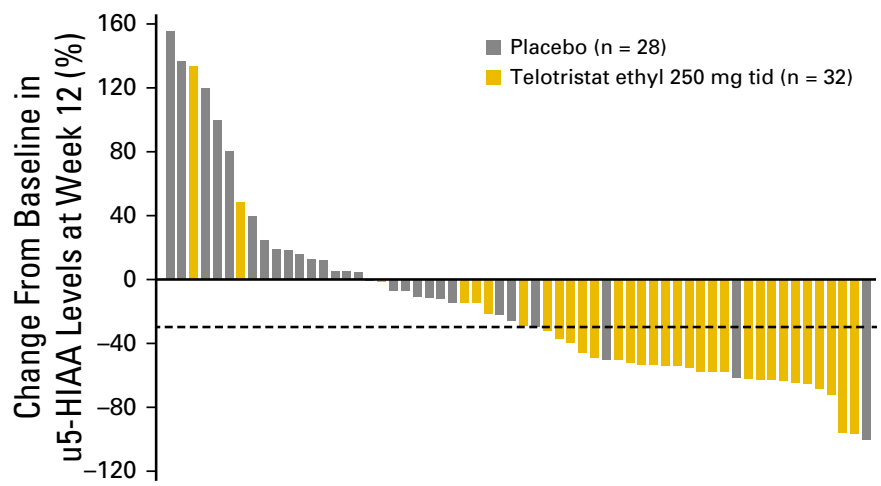

B

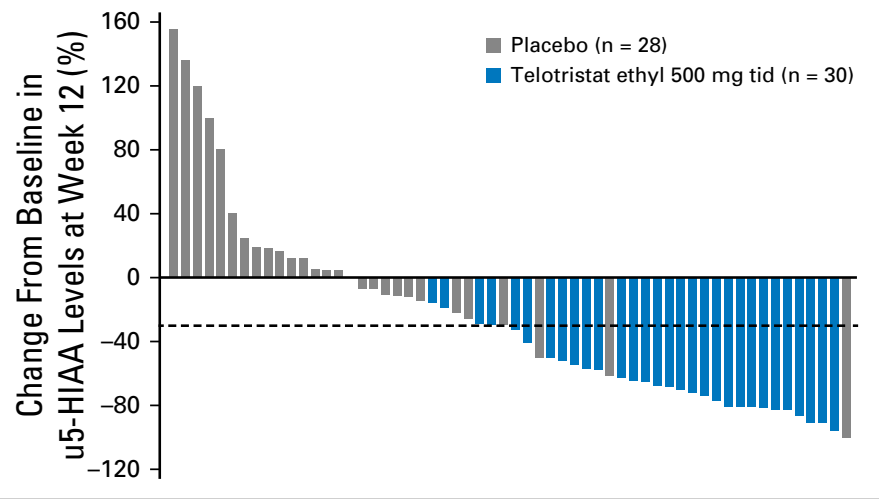

Fig 3. Percentage change from baseline in urinary 5-hydyroxyindoleacetic acid (u5-HIAA) levels at week 12. (A and B) Distribution of individual patient responses as

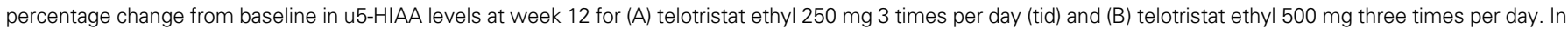

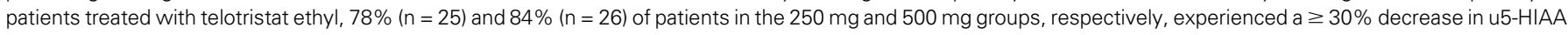

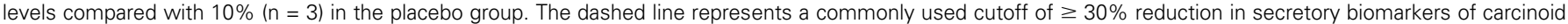
syndrome. $^{27}$

controlled on SSA therapy, treatment with the oral TPH inhibitor telotristat ethyl was associated with statistically significant reductions in BM frequency compared with placebo. Marked decreases in u5-HIAA were also associated with treatment. Although the overall incidence of TEAEs was similar across all treatment groups, nausea and elevated gamma-glutamyl transferase were reported more often in patients receiving telotristat ethyl. In patients receiving subsequent treatment in the OLE, reductions in BM frequency seemed to be sustained, and no new safety signals were observed. To our knowledge, this study represents one of the largest randomized placebo-controlled studies conducted to date to assess symptom control in patients with carcinoid syndrome.

SSAs, including octreotide and lanreotide, are widely used for the treatment of carcinoid syndrome, but not all patients achieve complete symptom control. ${ }^{4,17,18}$ Moreover, patients with carcinoid syndrome often live for years and may develop recurrent symptoms. ${ }^{4,6}$ There are few other treatment options, and the development of new treatments for carcinoid syndrome has proved challenging, in part because of the rarity of the condition and the lack of new drug candidates. $^{19-21}$

$\mathrm{BM}$ frequency is a useful end point in carcinoid syndrome studies because of its impact on patient function ${ }^{3}$ and well-being. A decrease of approximately three BMs per day (from a baseline of five to six BMs per day) was reported with octreotide LAR in patients with carcinoid syndrome. ${ }^{17}$ In this study, in patients experiencing diarrhea despite concomitant SSA therapy, BM frequency decreased by approximately two BMs per day with telotristat ethyl.

We performed a prespecified responder analysis, defining responders as patients experiencing $\geq 30 \%$ decrease in BM frequency for $\geq 50 \%$ of the DBT period, thereby measuring both magnitude and duration of response. ${ }^{10,11}$ More than $40 \%$ of patients treated with telotristat ethyl were responders versus $20 \%$ of patients treated with placebo.

Consistent with these observations, we also observed improvements in quality of life using the EORTC QLQ-C30 diarrhea subscale. No differences in the EORTC QLQ-C30 global health scores were observed. In fact, these scores were similar across all three treatment arms, suggesting that no quality of life detriment was associated with treatment. Interestingly, only minimal changes in overall EORTC QLQ-C30 global health scores were observed in previous studies in patients with NETs who received SSAs, suggesting that this domain may not be particularly sensitive in this patient population. $^{22-24}$

The BM response rate of $20 \%$ in the placebo group was a somewhat unexpected observation in our study. Although the placebo effect is well documented in clinical trials, ${ }^{25,26} \mathrm{BM}$ frequency is a relatively robust and objective end point and, in theory, should not be susceptible to subjective reporting. Use of short-acting rescue SSA therapy was somewhat more common in the placebo arm of this study and may have partially accounted for our observations. In addition, variability in the absorption of long-acting SSAs, differences in use of other antidiarrheal medications, and dietary changes may have contributed to the responses observed in the placebo group.

Treatment with telotristat ethyl significantly reduced u5-HIAA levels, suggesting effective TPH inhibition. u5-HIAA levels may vary for other reasons, and in prior studies of patients with NETs, $\geq 30 \%$ reduction in secretory biomarkers has been used as a measure of treatment efficacy to reduce the risk of capturing natural variability. ${ }^{27}$ In this study, $>78 \%$ of patients treated with telotristat ethyl (at either dosage) experienced $\mathrm{a} \geq 30 \%$ decrease in u5-HIAA levels versus $10 \%$ in the placebo group. The broader clinical significance of decreasing systemic serotonin levels, as determined by u5-HIAA levels, in patients with carcinoid syndrome has not been fully established. However, serotonin stimulates fibroblast proliferation and has been linked to cardiac valvular fibrosis in patients with carcinoid syndrome. ${ }^{28}$ Serotonin may also mediate mesenteric fibrosis often observed in patients with small intestine NETs. ${ }^{29}$ Future studies examining whether these complications of carcinoid syndrome can be prevented by reducing serotonin production with telotristat ethyl are warranted.

Similar reductions in BM frequency were observed at both telotristat ethyl dosages; however, over time, numerically greater reductions in BM frequency were observed with telotristat ethyl 


\begin{tabular}{|c|c|c|c|}
\hline \multirow[b]{2}{*}{ Category } & \multirow[b]{2}{*}{ Placebo $(n=45)$} & \multicolumn{2}{|c|}{ Telotristat Ethyl (three times per day) } \\
\hline & & $250 \mathrm{mg}(\mathrm{n}=45)$ & $500 \mathrm{mg}(\mathrm{n}=45)$ \\
\hline Any TEAE & $39(86.7)$ & $37(82.2)$ & $42(93.3)$ \\
\hline Study discontinuation as a result of TEAE* & $6(13.3)$ & $3(6.7)$ & $3(6.7)$ \\
\hline TEAE resulting in death $t$ & $3(6.7)$ & $1(2.2)$ & $1(2.2)$ \\
\hline \multicolumn{4}{|l|}{$\begin{array}{l}\text { Selected AEs occurring in } \geq 5 \% \text { of patients } \\
\text { in any study arm by system organ class } \\
\text { and preferred term } \neq\end{array}$} \\
\hline \multicolumn{4}{|l|}{ GI disorders } \\
\hline Nausea & $5(11.1)$ & $6(13.3)$ & $14(31.1)$ \\
\hline Abdominal pain & $8(17.8)$ & $5(11.1)$ & $10(22.2)$ \\
\hline Vomiting & $4(8.9)$ & $2(4.4)$ & $5(11.1)$ \\
\hline Abdominal distension & $3(6.7)$ & $2(4.4)$ & $1(2.2)$ \\
\hline Diarrhea & $3(6.7)$ & $3(6.7)$ & 0 \\
\hline Dyspepsia & $3(6.7)$ & $1(2.2)$ & $1(2.2)$ \\
\hline \multicolumn{4}{|c|}{ General disorders and administration site conditions } \\
\hline Fatigue & $4(8.9)$ & $4(8.9)$ & $7(15.6)$ \\
\hline \multicolumn{4}{|l|}{ Infections and infestations } \\
\hline Nasopharyngitis & $1(2.2)$ & $2(4.4)$ & $3(6.7)$ \\
\hline Pneumonia & 0 & 0 & $3(6.7)$ \\
\hline \multicolumn{4}{|l|}{ AEs relating to investigations } \\
\hline Increased gamma-glutamyl transferase§ & 0 & $4(8.9)$ & $4(8.9)$ \\
\hline Increased ALT\| & 0 & $1(2.2)$ & $3(6.7)$ \\
\hline Increased alkaline phosphatase $\|$ & 0 & 0 & $3(6.7)$ \\
\hline \multicolumn{4}{|l|}{ Metabolism and nutrition disorders } \\
\hline Decreased appetite & $2(4.4)$ & $3(6.7)$ & $7(15.6)$ \\
\hline Hypokalemia & $3(6.7)$ & $3(6.7)$ & $5(11.1)$ \\
\hline \multicolumn{4}{|l|}{ Nervous system disorders } \\
\hline Headache & $2(4.4)$ & $5(11.1)$ & $4(8.9)$ \\
\hline Dizziness & $2(4.4)$ & 0 & $4(8.9)$ \\
\hline Memory impairment & $3(6.7)$ & 0 & $1(2.2)$ \\
\hline \multicolumn{4}{|l|}{ Psychiatric disorders } \\
\hline Depression-related\# & $3(6.7)$ & $3(6.7)$ & $7(15.6)$ \\
\hline Confusional state & 0 & 0 & $3(6.7)$ \\
\hline \multicolumn{4}{|l|}{ Respiratory, thoracic, and mediastinal disorders } \\
\hline Dyspnea & 0 & $2(4.4)$ & $4(8.9)$ \\
\hline Cough & $1(2.2)$ & $1(2.2)$ & $3(6.7)$ \\
\hline \multicolumn{4}{|l|}{ Vascular disorders (new or worsening) } \\
\hline Flushing & $2(4.4)$ & $3(6.7)$ & $3(6.7)$ \\
\hline \multicolumn{4}{|c|}{ 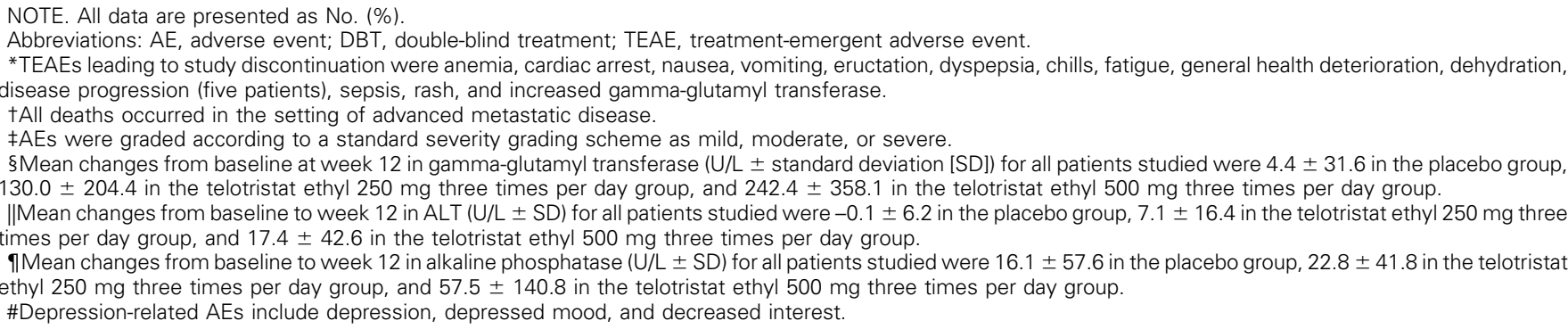 } \\
\hline
\end{tabular}

$500 \mathrm{mg}$ from weeks 7 to 12 . Reductions in u5-HIAA levels and in the EORTC QLQ-C30 diarrhea subscale, the proportion of days with the urgency to defecate, and improvements in stool consistency were also numerically greater with telotristat ethyl $500 \mathrm{mg}$. Telotristat ethyl $500 \mathrm{mg}$ demonstrated a favorable long-term tolerability profile, suggesting that this dose may be beneficial to patients not adequately responding to initial treatment with telotristat ethyl $250 \mathrm{mg}$.

Telotristat ethyl was generally well tolerated in this patient population. Increases in transaminases and nausea were observed in previous studies of telotristat ethyl. ${ }^{11,12}$ In this study, these events did not result in treatment discontinuation in patients randomly assigned to receive telotristat ethyl. Telotristat ethyl did not appear to be associated with an increased incidence of serious TEAEs. Preclinical studies suggest that telotristat ethyl does not have significant CNS penetration. ${ }^{5}$ In this study, a higher incidence of depression-related events was observed in patients who received telotristat ethyl $500 \mathrm{mg}$ than in patients who received placebo; however, incidences in patients who received telotristat ethyl $250 \mathrm{mg}$ and placebo were nearly identical. Most events resolved on study, and no new antidepressant therapies were initiated. In the current interim analysis of the OLE, rates of depression-related events have been relatively low. However, these data may be subject to some degree of selection bias and should be interpreted with caution. Additional follow-up in the 
ongoing OLE and evaluation of safety data in a separate ongoing phase III study (clinical trial information: NCT02063659) are planned.

In conclusion, treatment with the oral TPH inhibitor telotristat ethyl ( $250 \mathrm{mg}$ or $500 \mathrm{mg}$ three times per day) was generally safe and well tolerated and was associated with a significant decrease in BM frequency in patients with carcinoid syndrome receiving treatment with SSAs. The associated decreases in u5-HIAA provide evidence that telotristat ethyl effectively decreases serotonin production and has the potential to mitigate serotoninmediated complications in this patient population. These observations suggest that telotristat ethyl represents a potential new treatment approach for patients with carcinoid syndrome.

\section{AUTHORS' DISCLOSURES OF POTENTIAL CONFLICTS OF INTEREST}

Disclosures provided by the authors are available with this article at ascopubs.org/journal/jco.

\section{AUTHOR CONTRIBUTIONS}

Conception and design: Matthew H. Kulke, Lowell B. Anthony, Kjell Öberg, Enrique Grande, Douglas Fleming, Pablo Lapuerta, Phillip Banks, Shanna Jackson, Brian Zambrowicz, Arthur T. Sands, Marianne Pavel Provision of study materials or patients: Matthew H. Kulke, Dieter Hörsch, Martyn Caplin, Staffan Welin, Emily Bergsland, Richard R.P. Warner, Catherine Lombard-Bohas, Pamela L. Kunz, Enrique Grande, Juan W. Valle, Marianne Pavel

Collection and assembly of data: Dieter Hörsch, Martyn E. Caplin, Lowell B. Anthony, Kjell Öberg, Staffan Welin, Richard R.P. Warner, Catherine Lombard-Bohas, Pamela L. Kunz, Juan W. Valle, Douglas Fleming, Pablo Lapuerta, Shanna Jackson, Brian Zambrowicz, Marianne Pavel Data analysis and interpretation: Matthew H. Kulke, Dieter Hörsch, Martyn E. Caplin, Lowell B. Anthony, Emily Bergsland, Kjell Öberg, Pamela L. Kunz, Enrique Grande, Juan W. Valle, Douglas Fleming, Pablo Lapuerta, Phillip Banks, Shanna Jackson, Brian Zambrowicz, Marianne Pavel

Manuscript writing: All authors

Final approval of manuscript: All authors Accountable for all aspects of the work: All authors

\section{REFERENCES}

1. Mocellin S, Nitti D: Gastrointestinal carcinoid: Epidemiological and survival evidence from a large population-based study ( $n=25$ 531). Ann Oncol 24 : 3040-3044, 2013

2. Fox DJ, Khattar RS: Carcinoid heart disease Presentation, diagnosis, and management. Heart 90: 1224-1228, 2004

3. Beaumont JL, Cella D, Phan AT, et al: Comparison of health-related quality of life in patients with neuroendocrine tumors with quality of life in the general US population. Pancreas 41: 461-466, 2012

4. Boudreaux JP, Klimstra DS, Hassan MM, et al: The NANETS consensus guideline for the diagnosis and management of neuroendocrine tumors: Welldifferentiated neuroendocrine tumors of the jejunum, ileum, appendix, and cecum. Pancreas 39 753-766, 2010

5. Liu Q, Yang Q, Sun W, et al: Discovery and characterization of novel tryptophan hydroxylase in hibitors that selectively inhibit serotonin synthesis in the gastrointestinal tract. J Pharmacol Exp Ther 325: 47-55, 2008

6. National Cancer Institute: Gastrointestinal Carcinoid Tumors Treatment (PDO®)-Health Professional Version. https://www.cancer.gov/types/ gi-carcinoid-tumors/hp/gi-carcinoid-treatment-pdq

7. Kulke $M H$, Benson $A B$, Bergsland $E$, et al: National Comprehensive Cancer Network: Neuroendocrine Tumors, Clinical Practice Guidelines in Oncology. J Natl Compr Care Netw 10:724-764, 2012

8. Novartis Pharmaceuticals: Prescribing information for Sandostatin LAR. East Hanover, NJ, Novartis Pharmaceuticals, revised 7/16. http://wnw.pharma.us.novartis. com/product/pi/pdf/sandostatin_lar.pdf

9. Engelman K, Lovenberg W, Sjoerdsma A: Inhibition of serotonin synthesis by para-chlorophenylalanine in patients with the carcinoid syndrome. N Engl J Med 277:1103-1108, 1967
10. Lapuerta $P$, Zambrowicz $B$, Fleming $D$, et al: Telotristat etiprate, a novel inhibitor of serotonin synthesis for the treatment of carcinoid syndrome. Clin Investig (Lond) 5:447-456, 2015

11. Kulke $M H$, O'Dorisio $T$, Phan $A$, et al: Telotristat etiprate, a novel serotonin synthesis inhibitor, in patients with carcinoid syndrome and diarrhea not adequately controlled by octreotide. Endocr Relat Cancer 21:705-714, 2014

12. Pavel M, Hörsch D, Caplin M, et al: Telotristat etiprate for carcinoid syndrome: A single-arm, multicenter trial. J Clin Endocrinol Metab 100:1511-1519, 2015

13. Tellez MR, Mamikunian G, O'Dorisio TM, et al: A single fasting plasma 5-HIAA value correlates with 24-hour urinary 5-HIAA values and other biomarkers in midgut neuroendocrine tumors (NETs). Pancreas 42:405-410, 2013

14. Strosberg J, Weber J, Feldman $M$, et al: Above-label doses of octreotide-LAR in patients with metastatic small intestinal carcinoid tumors. Gastrointest Cancer Res 6:81-85, 2013

15. Whooley MA, Avins AL, Miranda J, et al: Casefinding instruments for depression: Two questions are as good as many. J Gen Intern Med 12:439-445, 1997

16. Ipsen Biopharmaceuticals: Prescribing information for Somatuline depot (lanreotide). Basking Ridge, NJ, Ipsen Biopharmaceuticals, revised 12/14. http://www.accessdata.fda.gov/drugsatfda_docs/ label/2014/022074s011lbl.pdf

17. Rubin J, Ajani J, Schirmer W, et al: Octreotide acetate long-acting formulation versus open-label subcutaneous octreotide acetate in malignant carcinoid syndrome. J Clin Oncol 17:600-606, 1999

18. Ruszniewski $P$, Ducreux $M$, Chayvialle JA, et al: Treatment of the carcinoid syndrome with the longacting somatostatin analogue lanreotide: A prospective study in 39 patients. Gut 39 : 279-283, 1996

19. American Society of Clinical Oncology, Cancer.net: Carcinoid tumor: Statistics. http://www cancer.net/cancer-types/carcinoid-tumor/statistics
20. Kulke MH, Siu LL, Tepper JE, et al: Future directions in the treatment of neuroendocrine tumors: Consensus report of the National Cancer Institute Neuroendocrine Tumor clinical trials planning meeting. J Clin Oncol 29:934-943, 2011

21. Wolin EM, Jarzab B, Eriksson B, et al: Phase III study of pasireotide long-acting release in patients with metastatic neuroendocrine tumors and carcinoid symptoms refractory to available somatostatin analogues. Drug Des Devel Ther 9 : 5075-5086, 2015

22. Chau I, Casciano R, Willet J, et al: Quality of life, resource utilisation and health economics assessment in advanced neuroendocrine tumours: A systematic review. Eur J Cancer Care (Engl) 22: 714-725, 2013

23. Jiménez-Fonseca $P$, Carmona-Bayonas $A$ Martín-Pérez $E$, et al: Health-related quality of life in well-differentiated metastatic gastroenteropancreatic neuroendocrine tumors. Cancer Metastasis Rev 34: 381-400, 2015

24. Yadegarfar $G$, Friend $L$, Jones $L$, et al: Validation of the EORTC QLQ-GINET21 questionnaire for assessing quality of life of patients with gastrointestinal neuroendocrine tumours. Br J Cancer 108:301-310, 2013

25. Kleijnen $\mathrm{J}$, de Craen AJ, van Everdingen $\mathrm{J}$ et al: Placebo effect in double-blind clinical trials: A review of interactions with medications. Lancet 344 : 1347-1349, 1994

26. American Cancer Society: Placebo effect. http:// www.cancer.org/treatment/treatmentsandsideeffects/ treatmenttypes/placebo-effect

27. Yao JC, Pavel M, Phan AT, et al: Chromogranin $A$ and neuron-specific enolase as prognostic markers in patients with advanced pNET treated with everolimus. J Clin Endocrinol Metab 96: 3741-3749, 2011

28. Hutcheson JD, Setola $V$, Roth $B L$, et al: Serotonin receptors and heart valve disease: It was meant 2B. Pharmacol Ther 132:146-157, 2011

29. Druce M, Rockall A, Grossman AB: Fibrosis and carcinoid syndrome: From causation to future therapy. Nat Rev Endocrinol 5:276-283, 2009 


\section{Affiliations}

Matthew H. Kulke, Dana-Farber Cancer Institute, Boston; Douglas Fleming, Ipsen Bioscience, Cambridge, MA; Dieter Hörsch, Zentralklinik Bad Berka, Bad Berka; Marianne Pavel, Charité-Universitätsmedizin, Berlin, Germany; Martyn E. Caplin, Royal Free Hospital, London; Juan W. Valle, The University of Manchester-The Christie National Health Service Foundation Trust, Manchester, United Kingdom; Lowell B. Anthony, University of Kentucky, Lexington, KY; Emily Bergsland, University of California at San Francisco Helen Diller Family Comprehensive Cancer Center, San Francisco; Pamela L. Kunz, Stanford University, Palo Alto, CA; Kjell Öberg and Staffan Welin, Uppsala University, Uppsala, Sweden; Richard R.P. Warner, Icahn School of Medicine at Mount Sinai, New York, NY; Catherine Lombard-Bohas, Hôpital Edouard Herriot, Hospices Civils de Lyon, Lyon, France; Pablo Lapuerta, Phillip Banks, Shanna Jackson, Brian Zambrowicz, and Arthur T. Sands, Lexicon Pharmaceuticals, The Woodlands, TX; and Enrique Grande, Hospital Universitario Ramón y Cajal, Madrid, Spain.

Supported by Lexicon Pharmaceuticals.

\section{Support}

\section{Encourage Your Patients to Read the Cancer.Net Blog}

In an effort to share the most timely cancer information with patients and their families, Cancer.Net includes a patient information blog that covers current events, breaking news about cancer advances, and other items of patient interest. Penned by ASCO experts and staff, patients, and patient advocates, the Cancer.Net Blog is conversational in tone and authoritative in content. Tell your patients about the Cancer.Net Blog at www.cancer.net/blog. 
Telotristat Ethyl, a Tryptophan Hydroxylase Inhibitor for the Treatment of Carcinoid Syndrome

The following represents disclosure information provided by authors of this manuscript. All relationships are considered compensated. Relationships are self-held unless noted. I = Immediate Family Member, Inst = My Institution. Relationships may not relate to the subject matter of this manuscript. For more information about ASCO's conflict of interest policy, please refer to www.asco.org/rwc or ascopubs.org/jco/site/ifc.

Matthew H. Kulke

Consulting or Advisory Role: Novartis, Ipsen Biopharmaceuticals, Lexicon Pharmaceuticals

\section{Dieter Hörsch}

Honoraria: Lexicon Pharmaceuticals, Ipsen Biopharmaceuticals, Novartis, Pfizer

Consulting or Advisory Role: Lexicon Pharmaceuticals,

Ipsen Biopharmaceuticals, Pfizer, Novartis

Research Funding: Novartis

Travel, Accommodations, Expenses: Pfizer, Novartis, Ipsen Biopharmaceuticals

\section{Martyn E. Caplin}

Honoraria: Novartis, Ipsen Biopharmaceuticals, Lexicon Pharmaceuticals Consulting or Advisory Role: Novartis, Ipsen Biopharmaceuticals,

Lexicon Pharmaceuticals

Speakers' Bureau: Novartis, Ipsen Biopharmaceuticals

Research Funding: Novartis, Lexicon Pharmaceuticals, Ipsen

Biopharmaceuticals

Travel, Accommodations, Expenses: Novartis, Ipsen Biopharmaceuticals, Lexicon Pharmaceuticals

Lowell B. Anthony

Consulting or Advisory Role: Lexicon Pharmaceuticals

Research Funding: Lexicon Pharmaceuticals

Travel, Accommodations, Expenses: Lexicon Pharmaceuticals

Emily Bergsland

Employment: MORE Health (I)

Consulting or Advisory Role: MORE Health, Ipsen Biopharmaceuticals, Lexicon Pharmaceuticals, Novartis

Research Funding: Novartis (Inst)

Patents, Royalties, Other Intellectual Property: Receives royalties from UptoDate for editing chapters

\section{Kjell Öberg}

Honoraria: Novartis, Ipsen Biopharmaceuticals

Consulting or Advisory Role: Novartis, Ipsen Biopharmaceuticals Speakers' Bureau: Ipsen Biopharmaceuticals, Novartis

Travel, Accommodations, Expenses: Ipsen Biopharmaceuticals, Novartis

\section{Staffan Welin}

Honoraria: Novartis, Ipsen Biopharmaceuticals

Consulting or Advisory Role: Novartis, Ipsen Biopharmaceuticals

Travel, Accommodations, Expenses: Novartis, Ipsen Biopharmaceuticals

Richard R.P. Warner

Consulting or Advisory Role: Lexicon Pharmaceuticals, Ipsen

Biopharmaceuticals

Research Funding: Lexicon Pharmaceuticals (Inst)

Catherine Lombard-Bohas

Consulting or Advisory Role: Novartis, Ipsen Biopharmaceuticals

Pamela L. Kunz

Consulting or Advisory Role: Ipsen Biopharmaceuticals, Novartis, Lexicon Pharmaceuticals

Research Funding: Advanced Accelerator Applications (Inst), Genentech (Inst), Merck (Inst), Lexicon Pharmaceuticals (Inst), Novartis (Inst), OXiGENE (Inst), Esanex (Inst), Ipsen Biopharmaceuticals (Inst)

Enrique Grande

Consulting or Advisory Role: Lexicon Pharmaceuticals,

Ipsen Biopharmaceuticals
Juan W. Valle

Honoraria: Ipsen Biopharmaceuticals, Celgene, Novartis, AstraZeneca, Advanced Accelerator Applications, Sirtex Medical, Midatech Pharma, Eli Lilly, Merck, Baxalta

Consulting or Advisory Role: Ipsen Biopharmaceuticals, Sirtex Medical, Celgene, Novartis, AstraZeneca, Advanced Accelerator Applications, Eli Lilly, Merck, Baxalta

Speakers' Bureau: Pfizer, Novartis, Abbott Nutrition, Celgene, Ipsen Biopharmaceuticals, Sirtex Medical

Research Funding: Novartis (Inst), AstraZeneca (Inst)

Travel, Accommodations, Expenses: Novartis, Celgene

\section{Douglas Fleming}

Employment: Lexicon Pharmaceuticals, Ipsen Bioscience, Bristol-Myers Squibb

Leadership: Lexicon Pharmaceuticals, Ipsen Bioscience

Stock or Other Ownership: Lexicon Pharmaceuticals, Ipsen Bioscience, Bristol-Myers Squibb

\section{Pablo Lapuerta}

Employment: Lexicon Pharmaceuticals

Leadership: Lexicon Pharmaceuticals

Stock or Other Ownership: Lexicon Pharmaceuticals, Merck

Travel, Accommodations, Expenses: Lexicon Pharmaceuticals

Phillip Banks

Employment: Lexicon Pharmaceuticals

Stock or Other Ownership: Lexicon Pharmaceuticals

Travel, Accommodations, Expenses: Lexicon Pharmaceuticals

Other Relationship: Lexicon Pharmaceuticals

\section{Shanna Jackson}

Employment: Lexicon Pharmaceuticals

Stock or Other Ownership: Lexicon Pharmaceuticals

Travel, Accommodations, Expenses: Lexicon Pharmaceuticals

\section{Brian Zambrowicz}

Employment: Lexicon Pharmaceuticals, Regeneron Pharmaceuticals Leadership: Lexicon Pharmaceuticals, Regeneron Pharmaceuticals

Stock or Other Ownership: Lexicon Pharmaceuticals, Regeneron

Pharmaceuticals

Consulting or Advisory Role: Lexicon Pharmaceuticals

Patents, Royalties, Other Intellectual Property: Lexicon: Inventor on pending US patents regarding methods and compounds for inhibiting tryptophan hydroxylase. Regeneron: Inventor on patent applications unrelated to this study.

\section{Arthur T. Sands}

Employment: Lexicon Pharmaceuticals, Nurix

Leadership: Lexicon Pharmaceuticals, Nurix

Stock or Other Ownership: Lexicon Pharmaceuticals, Nurix

Consulting or Advisory Role: Lexicon Pharmaceuticals

\section{Marianne Pavel}

Honoraria: Novartis, Ipsen Biopharmaceuticals, Pfizer, Lexicon

Pharmaceuticals

Consulting or Advisory Role: Novartis, Ipsen Biopharmaceuticals, Pfizer,

Lexicon Pharmaceuticals

Speakers' Bureau: Novartis

Research Funding: Novartis, Ipsen Biopharmaceuticals 


\section{Acknowledgment}

Presented in part at the European Cancer Congress 2015, Vienna, Austria, September 25-29, 2015; North American Neuroendocrine Tumor Society Symposium Austin, Austin, TX, October 15-17, 2015; 12th Annual European Neuroendocrine Tumor Society (ENETS) Conference, Barcelona, Spain, March 11-13, 2015; and the 13th Annual ENETS Conference, Barcelona, Spain, March 9-11, 2016. We thank the patients and investigators for participating in the study and the Lexicon scientists who had the vision to develop a novel tryptophan hydroxylase inhibitor and successfully created telotristat ethyl. We thank Ammy Santiago, Chameleon Communications International (with funding provided by Lexicon Pharmaceuticals), for medical editorial assistance with this manuscript. We thank the following Lexicon employees: Linda Law for medical oversight during study initiation, Kenneth Kassler-Taub for oversight of clinical operations, Karie Arnold for clinical site management for the North American region, Ernest Wang for study monitoring, Rosanna Fleming for statistical analysis, Nam Wommack for data management, Heena Pandya and Wenjun Jiang for safety monitoring, and Kristi A. Boehm for her assistance with figure preparation, text formatting, and editing of this manuscript. We also thank the team at INC Research (Raleigh, NC) for study conduct, monitoring, analysis, and reporting.

\section{Appendix}

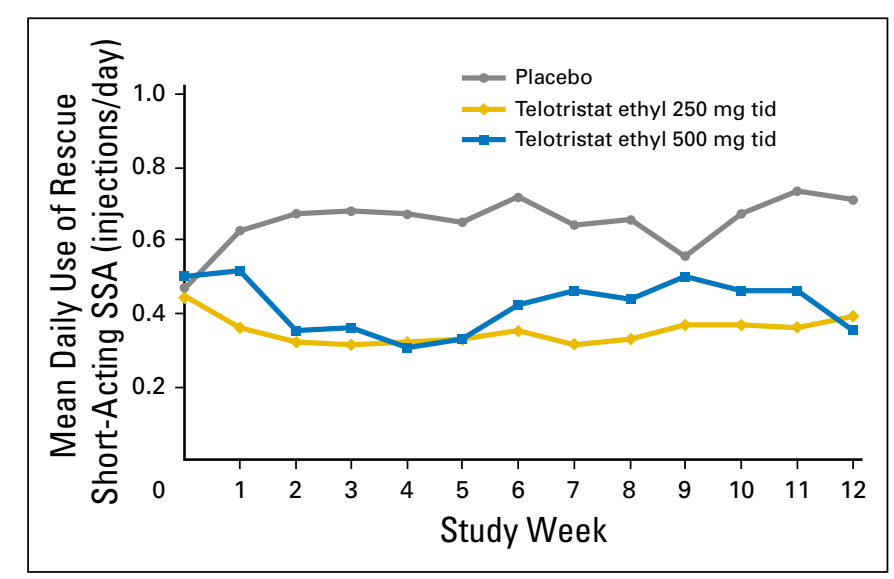

Fig A1. Mean daily use of rescue short-acting somatostatin analog (SSA) therapy in the double-blind treatment period. Some evidence that treatment with telotristat ethyl decreased the use of rescue short-acting SSA therapy was observed during the double-blind treatment period. 
Table A1. Additional Secondary End Points of the DBT Period

\begin{tabular}{|c|c|c|c|c|c|c|}
\hline Variable & \multicolumn{2}{|c|}{ Placebo $(n=45)$} & \multicolumn{2}{|c|}{$250 \mathrm{mg}(\mathrm{n}=45)$} & \multicolumn{2}{|c|}{$500 \mathrm{mg}(\mathrm{n}=45)$} \\
\hline \multicolumn{7}{|l|}{ Flushing } \\
\hline $\begin{array}{l}\text { Change from baseline in daily flushing episodes averaged } \\
\text { over } 12 \text { weeks, counts per day }\end{array}$ & $-0.16(1.16)$ & & $-0.30(1.31)$ & & $-0.53(1.34)$ & \\
\hline \multicolumn{7}{|l|}{ Abdominal pain } \\
\hline $\begin{array}{l}\text { Change from baseline in abdominal pain averaged over } 12 \\
\text { weeks, points } t\end{array}$ & $-0.23(1.16)$ & & $-0.49(1.44)$ & & $-0.33(1.18)$ & \\
\hline Arithmetic mean treatment difference & - & & -0.26 & & -0.11 & \\
\hline Hodges-Lehmann estimator* & - & - & -0.17 & .28 & -0.05 & .87 \\
\hline \multicolumn{7}{|l|}{ Daily rescue short-acting SSA use } \\
\hline $\begin{array}{l}\text { Change from baseline in use of short-acting SSAs, averaged } \\
\text { over } 12 \text { weeks, injections per day }\end{array}$ & 0.18 & & -0.11 & & 0.03 & \\
\hline \multicolumn{7}{|l|}{ Stool consistency } \\
\hline $\begin{array}{l}\text { Change from baseline in stool consistency averaged over } 12 \\
\text { weeks, points }\end{array}$ & $-0.22(0.48)$ & & $-0.26(0.47)$ & & $-0.36(0.41)$ & \\
\hline Arithmetic mean treatment difference & - & & -0.05 & & -0.15 & \\
\hline Hodges-Lehmann estimator* & - & - & -0.09 & .57 & -0.15 & .052 \\
\hline \multicolumn{7}{|l|}{ Urgency to defecate } \\
\hline Proportion of days & $0.75(0.29)$ & & $0.67(0.34)$ & & $0.60(0.31)$ & \\
\hline Arithmetic mean treatment difference & - & & -0.09 & & -0.15 & \\
\hline Hodges-Lehmann estimator* & - & - & -0.02 & .35 & -0.13 & .006 \\
\hline
\end{tabular}

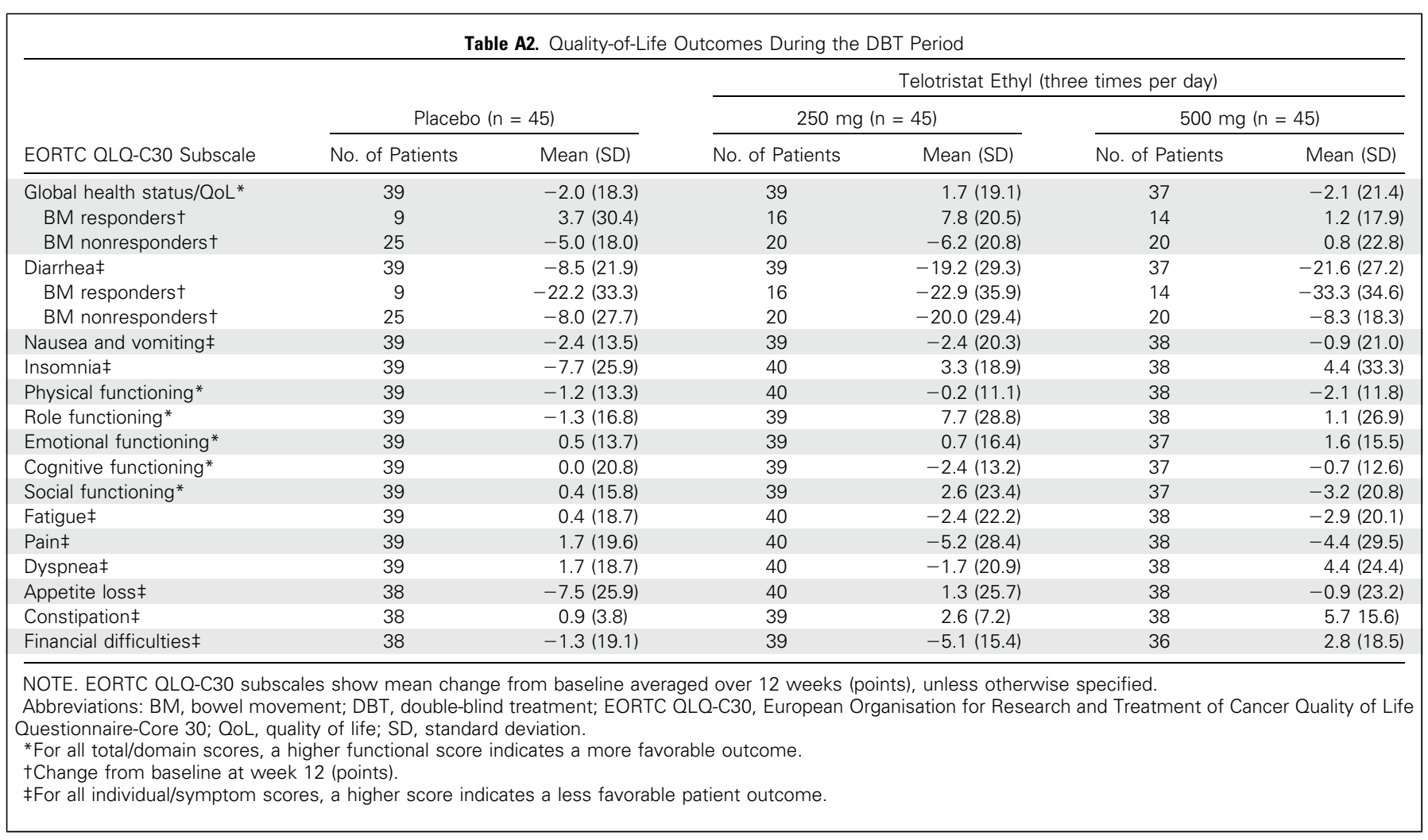


Table A3. All AEs Occurring in $\geq 5 \%$ of Patients in Any Study Arm in the DBT Period

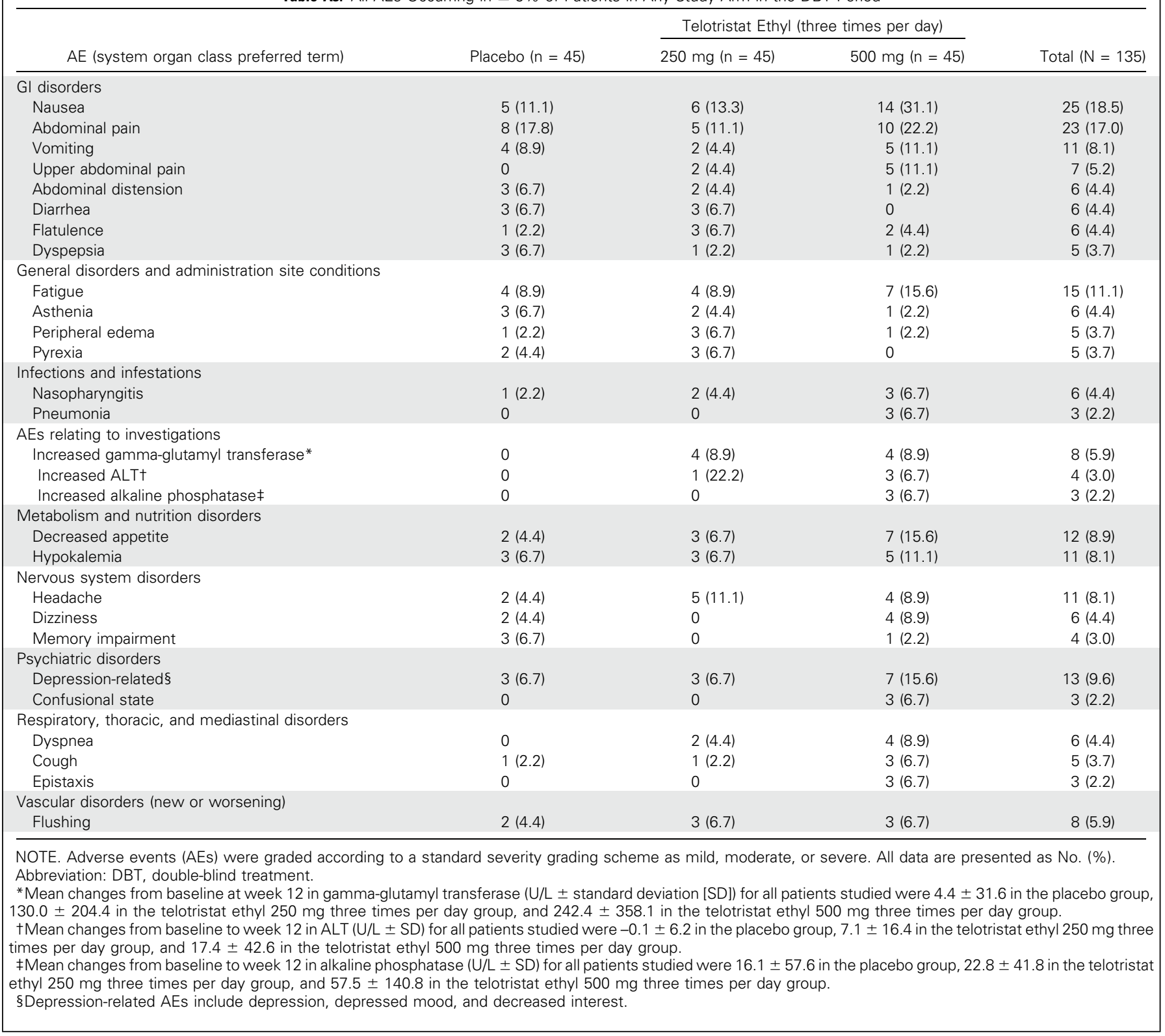


Kulke et al

Table A4. Summary of TEAEs Reported During the OLE

\begin{tabular}{lcr}
\hline & \multicolumn{2}{c}{$\operatorname{OLE}^{*}(\mathrm{n}=115)$} \\
\cline { 2 - 3 } \multicolumn{1}{c}{ Category } & No. & $\%$ \\
\hline Any TEAE & 105 & 91.3 \\
Any serious TEAE† & 36 & 31.3 \\
Study discontinuation as a result of TEAE & 14 & 12.2 \\
TEAE resulting in death§ & 8 & 7.0 \\
Selected key AEs & & \\
Any depression-related AE & 17 & 15.0 \\
Nausea & 23 & 20.0 \\
Increased gamma-glutamyl transferase & 7 & 6.1 \\
Increased alanine aminotransferase & 4 & 3.5 \\
Increased alkaline phosphatase & 5 & 4.3 \\
\hline
\end{tabular}

Abbreviations: AE, adverse event; OLE, open-label extension; TEAE, treatmentemergent adverse event.

*Patients were initiated at $500 \mathrm{mg}$ telotristat ethyl three times per day. Mean treatment exposure was 11.3 weeks in the double-blind treatment period and 26.7 weeks in the OLE.

tAEs were considered serious if they involved death, a life-threatening $A E$, inpatient hospitalization, a persistent or significant incapacity, substantial disruption in the ability to conduct normal life function, or a congenital anomaly or birth defect.

¥TEAEs leading to study discontinuation in the OLE were supraventricular tachycardia, disease progression (five patients), abdominal distension, constipation, GI hemorrhage, hematemesis, large intestine perforation, asthenia, fatigue, general physical health deterioration, hepatomegaly, peritonitis, sepsis, increased liver enzymes, decreased weight, decreased appetite, dehydration, mental confusion, cognitive disorder, renal failure, and urticaria.

$\S$ None of the deaths occurring during the OLE were considered related to study drug. The deaths were generally attributable to the progression or complication of the underlying disease.

१Depression-related AEs include depression, depressed mood, and decreased interest. 